\title{
Use of antidepressants during pregnancy in the Netherlands: observational study into postpartum interventions
}

\author{
Noera Kieviet ${ }^{1 *}$, Fokke de Jong ${ }^{2}$, Fedde Scheele ${ }^{3}$, Koert M. Dolman $^{1}$ and Adriaan Honig ${ }^{2,4}$
}

\begin{abstract}
Background: Psychiatric disorders and use of selective antidepressants during pregnancy can have negative effects on mother and infant postpartum. This study aimed to provide evidence-based recommendations on observation of antidepressant-exposed mother-infant dyads.

Methods: In this observational study, mother-infant dyads were observed for possible consequences of either the maternal psychiatric disorder or fetal exposure to selective antidepressants during pregnancy. These possible complications can lead to medical interventions, including 1. adjustment of antidepressants 2. admission to the psychiatric department 3. additional investigations due to indistinctness about the origin of neonatal symptoms 4. treatment of poor neonatal adaptation and 5. consultation of an external organization for additional care. The type, number and time to medical interventions were analyzed.
\end{abstract}

Results: In 61\% of the 324 included mother-infant dyads one or more intrventions were performed. Adjustment of antidepressants and treatment of poor neonatal adaptation were most prevalent. In $75 \%$ of dyads the final intervention was performed within $48 \mathrm{~h}$.

Conclusions: The high prevalence and type of medical interventions requires professional observation of all mother-infant dyads exposed to selective antidepressants. In the absence of specialized home care, hospital admission is indicated whereby an observational period of $48 \mathrm{~h}$ seems sufficient for most dyads.

Keywords: Pregnancy, Withdrawal, Observation, Finnegan, Depression

\section{Background}

Exposure to selective antidepressants during pregnancy, used by $2-9 \%$ of Western pregnant women $[1,2]$, can have postpartum consequences for mother and infant [3]. In addition, the maternal psychiatric disorder itself can also have negative consequences during this period [4]. Therefore, postpartum hospital observation of selective antidepressant-exposed mothers and their infants is common practice $[3,5,6]$. Unfortunately there are no guidelines concerning the type and duration of this observational period.

Possible consequences of the maternal psychiatric disorder include an increased risk of prematurity and

\footnotetext{
* Correspondence: noera.kieviet@gmail.com

'Department of Pediatrics, Psychiatry Obstetrics Pediatrics Expert Center OLVG West, Jan Tooropstraat 164, 1061 AE Amsterdam, The Netherlands

Full list of author information is available at the end of the article
}

low birth weight and a recurrence or worsening of psychiatric symptoms, which can impair the attachment between mother and infant [4, 7-11]. Approximately $20-30 \%$ of selective antidepressant-exposed infants develop poor neonatal adaptation due to exposure to selective antidepressants [3, 12-14]. Poor neonatal adaptation consists of symptoms of restlessness, such as feeding and sleeping difficulties, which are mostly mild and self-limiting. Because symptoms are nonspecific, differentiation from other, more severe, neonatal pathology such as perinatal infection, can be difficult $[3,5,13,14]$. Furthermore, some studies found that exposure to selective antidepressants may elevate the risk of other maternal and neonatal effects, such as postpartum hemorrhage, prematurity and persistent pulmonary hypertension of the newborn (PPHN). However other 
studies did not find a relation between exposure to selective antidepressant and these complications $[15,16]$.

Because the evaluation of possible maternal and neonatal effects need medical expertise or medical intervention, in the Netherlands, most caregivers advise hospital admission of mothers and their infants postpartum. However, the duration of this period differs per hospital.

Several experts advise an observational period of $48 \mathrm{~h}$, though guidelines or protocols are not available [5, 12, 17-19]. Evidence-based recommendations on this subject would improve the quality and uniformity of care. In order to develop such recommendations, insight into complications that lead to medical intervention is needed.

This observational study provides insight into the type and number, as well as the time to medical interventions during the first days postpartum. From these data, recommendations can be formulated with respect to the necessity of professional observation, type of observational setting and time period of observation.

\section{Methods \\ Setting}

We conducted an observational study in a teaching hospital in Amsterdam, the Netherlands. The psychiatric, obstetric, pediatric clinic of this hospital is a center of expertise for pregnancy and psychiatric disorders and advises women with a psychiatric disorder before, during and after pregnancy. Primary care givers (mainly general practitioners, midwifes, obstetricians and psychiatrists) refer patients to this clinic. Approximately $50 \%$ of all women who visit this clinic live in the catchment area and deliver in our hospital. In case of home birth, or birth in another hospital due to capacity problems in our hospital, within 8hours postpartum these women are admitted to the maternity ward, together with their infants.

During hospital admission, nurses, pediatricians, obstetricians and psychiatrists observe, evaluate, support and treat mother and infant for $72 \mathrm{~h}$. The psychiatrist evaluates possible psychiatric symptoms in mothers and adjusts the psychotropic medication if necessary (changes the dosage or type of psychotropic medication or starts additional medication). The psychiatrist uses the hospital anxiety and depression scale (HADS), which is a validated questionnaire for symptoms of anxiety and depression and is completed at the first day postpartum delivery $[20,21]$. If psychiatric care after hospital discharge is too limited or in case social problems, such as absence of a support system, are detected external organizations can be consulted. The obstetrician assesses the physical condition of the mother and treats complications if necessary. Infants are physically examined by the pediatrician and treated in case of pathology. Trained nurses assess poor neonatal adaptation in infants with use of the Finnegan scoring list three times a day [22]. This observational tool is used to monitor the moment of onset and development of symptoms of poor neonatal adaptation. A Finnegan score of four or higher is an indication for poor neonatal adaptation $[3,5,12]$. The pediatrician determines if PNA has been present or absent, based on the Finnegan scores and physical examination and observation. In case of indistinctness about the origin of symptoms, additional testing can be necessary to exclude other neonatal pathology, such as perinatal infection $[3,5,13,14]$. When poor neonatal adaptation has been diagnosed supportive measures such as swaddling are mostly sufficient. Infants with severe poor neonatal adaptation (multiple Finnegan scores of $\geq 8$ and severe symptoms such as convulsions) are admitted to the neonatal care unit and can be treated with phenobarbital. Parents are supported by explanation and reassurance. Furthermore, the team observes the motherinfant interaction. If interaction difficulties are present external organizations can be consulted to provide family care.

\section{Participants}

From January 1st 2007 to December 31st 2012 all mothers who used selective antidepressants during at least the last trimester of pregnancy and who were admitted in our hospital for observation together with their infants postpartum were included $(n=324)$. Selective antidepressants were defined as selective serotonin reuptake inhibitors, serotonin norepinephrine reuptake inhibitors, norepinephrine-dopamine reuptake inhibitors or noradrenergic and specific serotonergic antidepressants. Tricyclic antidepressants, were not included as these antidepressants have a different mechanism of action. However, if mothers used other types of antidepressants or other types of psychotropic drugs in combination with a selective antidepressants, mothers were included.

Exclusion criteria were use of illicit drugs [23] or regular alcohol use of more than two units per week during last trimester of pregnancy, admission to the psychiatric department up to delivery and postpartum transfer to another hospital. In order to create motherinfant dyads, in case of multiple pregnancies one infant was randomly selected.

\section{Interventions}

Mother-infant dyads were analyzed for medical interventions that had been performed during hospital admission, all caused by exposure to selective antidepressants or the maternal psychiatric disorder. These interventions were: 1 . adjustment of psychotropic medication 2. admission to 
the psychiatric department 3 . additional investigations due to indistinctness about the origin of neonatal symptoms whereby the final diagnose was poor neonatal adaptation. 4. treatment of poor neonatal adaptation and 5. consultation of an external organization for additional family care. The prevalence of interventions was established by calculating the percentage of mother-infant dyads in which one or more interventions were performed. All base-line characteristics were compared between motherinfant dyads in which an intervention was performed and dyads whereby no intervention was performed.

\section{Time to interventions}

For the first four interventions the time to intervention (hours postpartum) was analyzed. For the fifth intervention (consultation of an external organization for additional family care) time was not analyzed because organizations are generally contacted at hospital discharge.

Per mother-infant dyad the time to the final intervention was investigated. This was exclusively done for dyads in which times of all interventions were known.

The time to intervention was divided into $<12 \mathrm{~h}, 13-24$, 25-48, 49-72 and $>72 \mathrm{~h}$ postpartum. The time to the intervention 'treatment of poor neonatal adaptation' was defined as the moment of administration of pharmacotherapy or the moment of the first Finnegan score of four or higher in case of supportive treatment. The time to other interventions was established by the time noted in the patient files of mother and infant.

In order to examine if there are factors which are associated with late time of intervention, all base-line characteristics were compared between mother-infant dyads in which the final intervention was performed within $48 \mathrm{~h}$ and dyads in which the final intervention was performed after $48 \mathrm{~h}$ postpartum.

\section{Statistical analyses}

Data were analyzed by SPSS version 21 (IBM, New York, USA). In all continuous variables, the mean and standard deviation were presented in case of a normal distribution. Otherwise, the median and inter quartile range were presented. The base-line characteristics of mother-infant dyads in which an intervention was performed were compared to the characteristics of dyads in which no intervention was performed. Continuous, normally distributed variables were compared with the independent sample $t$ test. Continuous, skewed variables were compared with the Mann Whitney $U$ test. Dichotomous or categorical variables were compared with the chi square test. In case more than $20 \%$ of the expected cell counts were less than five the Fisher exact test was performed. A result was considered statistically significant if the $p$-value was not larger than 0.05 . The base-line characteristics of dyads in which the final intervention was performed within or after $48 \mathrm{~h}$ were compared in the same manner. In addition, odds ratios (OR) and $95 \%$ confidence intervals $(\mathrm{CI})$ were estimated using univariate analysis.

\section{Results \\ Patient characteristics}

In the period of January 1st 2007 till December 31st 2012, a total of 330 mothers who used selective antidepressants during at least the last trimester of pregnancy were admitted to the maternity ward of our hospital for observation. Two mothers delivered a twin, one of each twin was randomly excluded. One mother-infant dyad was excluded because the mother used soft drugs during pregnancy and five dyads were excluded because they were transferred to another hospital. In three dyads this transfer was based on severe medical problems, which were fluxus, neonatal breathing difficulties and neonatal asphyxia. In the end, 324 mother-infant dyads (98.2\%) were included (Fig. 1).

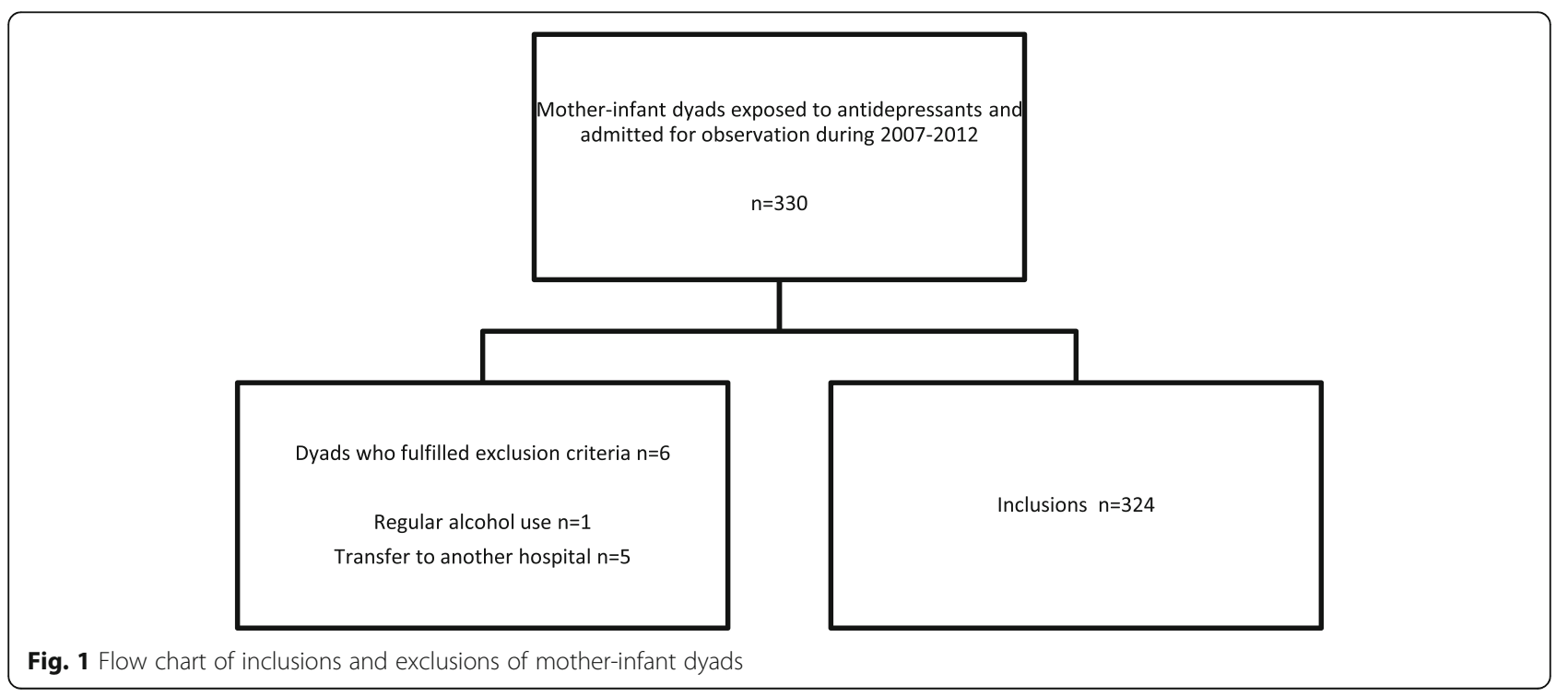


Table 1 Characteristics of mothers and infants

\begin{tabular}{|c|c|c|c|c|}
\hline Variables & $\begin{array}{l}\text { Total group } \\
n=324\end{array}$ & $\begin{array}{l}\text { Intervention } \\
n=143\end{array}$ & $\begin{array}{l}\text { No intervention } \\
n=181\end{array}$ & $p$-value \\
\hline & \multicolumn{4}{|c|}{ Median (inter quartile range) } \\
\hline Maternal age during delivery (years) & $33(29-36)$ & $32(29-36)$ & $33(29-36)$ & 0.59 \\
\hline Duration of observation mother (days) & $4(3-5)$ & $4(3-6)$ & $4(3-5)$ & 0.28 \\
\hline \multirow[t]{2}{*}{ Duration of observation infant (days) } & $4(3-5)$ & $4(3-5)$ & $4(3-5)$ & 0.14 \\
\hline & n (\%) & & & \\
\hline Marital status & & & & 0.80 \\
\hline Married/living together & $275(85.9)$ & $121(85.2)$ & $154(86.5)$ & \\
\hline Living Apart Together & $17(5.3)$ & $7(4.9)$ & $10(5.6)$ & \\
\hline Single & $28(8.8)$ & $14(9.9)$ & $14(7.9)$ & \\
\hline Unknown & 4 & 1 & 3 & \\
\hline Smoking & $31(9.8)$ & $16(11.6)$ & $15(8.5)$ & 0.36 \\
\hline Unknown & 9 & 5 & 4 & \\
\hline Type of psychotropic medication & & & & 0.37 \\
\hline Solely antidepressant & $291(89.8)$ & $126(88.1)$ & $165(91.2)$ & \\
\hline Antidepressant and other type of psychotropic drug & $33(10.2)$ & $17(11.9)$ & $16(8.8)$ & \\
\hline Dosage of antidepressant & & & & 0.003 \\
\hline Below minimal effective daily dosage & $20(6.2)$ & $8(5.6)$ & $12(6.6)$ & \\
\hline Minimal effective daily dosage & $146(45.2)$ & $50(35.2)$ & $96(53.0)$ & \\
\hline Above minimal effective daily dosage & $157(48.6)$ & $84(59.2)$ & $73(40.3)$ & \\
\hline Unknown & 1 & & & \\
\hline Primiparous & $144(44.4)$ & $65(45.5)$ & 79 (43.6) & 0.75 \\
\hline \multicolumn{5}{|l|}{$\mathrm{HADS}^{\mathrm{a}}$} \\
\hline Anxiety scale elevated & $131(42.5)$ & $75(55.1)$ & $67(39.0)$ & 0.02 \\
\hline Depression scale elevated & $93(30.2)$ & $68(50.0)$ & $63(36.6)$ & 0.01 \\
\hline One or both scales elevated & $142(46.1)$ & $75(55.1)$ & $67(39.0)$ & 0.01 \\
\hline Unknown & 16 & 7 & 9 & \\
\hline Gender infant male & $163(50.3)$ & $78(54.5)$ & $85(47.0)$ & 0.18 \\
\hline Type of birth & & & & 0.07 \\
\hline Vaginal, non-instrumental & $236(72.8)$ & $97(67.8)$ & $139(76.8)$ & \\
\hline Vaginal, instrumental & $37(11.4)$ & $16(11.2)$ & $21(11.6)$ & \\
\hline Caesarean Section & $51(15.7)$ & $30(21.0)$ & $21(11.6)$ & \\
\hline Type of feeding & & & & 0.02 \\
\hline Breastfeeding or mixed feeding & $250(77.4)$ & $101(71.1)$ & $149(82.3)$ & \\
\hline Exclusively formula & $73(22.6)$ & $41(28.9)$ & $32(17.7)$ & \\
\hline Unknown & 1 & & & \\
\hline Prematurity & $30(9.3)$ & $13(7.0)$ & $17(9.4)$ & 0.93 \\
\hline Finnegan score, highest during observation & & & & $<0.001$ \\
\hline$<4$ & $130(40.1)$ & $30(21.0)$ & $100(55.2)$ & \\
\hline $4-8$ & $156(48.1)$ & $80(55.9)$ & $76(42.0)$ & \\
\hline$\geq 8$ & $38(11.7)$ & $33(23.1)$ & $5(2.8)$ & \\
\hline
\end{tabular}

${ }^{\mathrm{a}}$ Hospital anxiety and depression scale 
Of these mothers, 304 mothers (93.8\%) delivered in our hospital, 13 mothers (4.0\%) delivered at home and 7 mothers (2.2\%) delivered in another hospital. The maternal and neonatal characteristics are presented in Table 1. Three mothers $(0.9 \%)$ decided to go home before medical discharge, all after at least $48 \mathrm{~h}$ of observation. Of the 324 mothers, 310 (95.7\%) were known with an affective disorder, some in combination with other psychiatric disorders. Of the 291 mothers who solely used an antidepressant, 209 used an selective serotonin reuptake inhibitors, 32 a serotonin norepinephrine reuptake inhibitors, 35 a noradrenergic and specific serotonergic antidepressants and 1 a norepinephrine-dopamine reuptake inhibitor. Fourteen mothers used a combination of antidepressants. See Appendix for an overview of antidepressants used in our study population.

\section{Interventions}

Of the 324 mother-infant dyads, a total of 143 dyads (61.1\%) needed one or more intervention. One intervention was performed in $70.6 \%$ of dyads. In $24.5 \%$ two and in $4.9 \%$ three or four interventions were performed.

In 76 mothers $(23.5 \%)$ the psychotropic medication was adjusted. The main reasons were symptoms of depression or anxiety and sleeping difficulties. No mothers had to be admitted to the psychiatric department. Nine infants $(2.8 \%)$ underwent additional tests due to indistinctness about the origin of neonatal symptoms. Additional testing, which included blood tests, brain ultrasounds, a chest radiograph and electroencephalography excluded other pathology where after poor neonatal adaptation was diagnosed in all nine infants. The pediatrician diagnosed poor neonatal adaptation in 76 infants (23.5\%). These infants showed mild symptoms of sleeping- as well as feeding difficulties, tremors and jitteriness. One infant was treated with phenobarbital as these symptoms of restlessness were more severe and prolonged. All other infants were treated with supportive measures. External support was organized for eight mother-infant dyads (2.5\%), which consisted of psychiatric home care, social welfare and support regarding infant development.

\section{Time to interventions}

The time to interventions are presented in Fig. 2. In 63 of the 143 dyads in which an intervention was performed, the time of at least one intervention was unknown. Thus, we analyzed time to the final intervention in 80 mother-infant dyads. In $67.5 \%$ of these dyads one intervention was performed and in $32.5 \%$ multiple interventions were performed. In 6 of the dyads (7.5\%), the final intervention was performed within $12 \mathrm{~h}$, in 28 (35\%) between 13 and $24 \mathrm{~h}$, in 26 (32.5\%) between 25 and $48 \mathrm{~h}$, in $16(20.0 \%)$ between 49 and 72 and in 4 (5.0\%) after $72 \mathrm{~h}$ postpartum.

Base-line characteristics were compared between mother-infant dyads in which the final intervention was performed within $48 \mathrm{~h}$ and dyads in which the final intervention was performed after $48 \mathrm{~h}$ postpartum (Table 2). This revealed no statistically significant differences.

\section{Discussion}

To the best of our knowledge, this is the first study presenting data on medical interventions during the course of postpartum observation of mother-infant dyads exposed to selective antidepressants during pregnancy. In $61 \%$ of all dyads one or more interventions were performed. The most prevalent interventions were adjustment of psychotropic medication and treatment of poor neonatal adaptation. As expected, the Finnegan scores

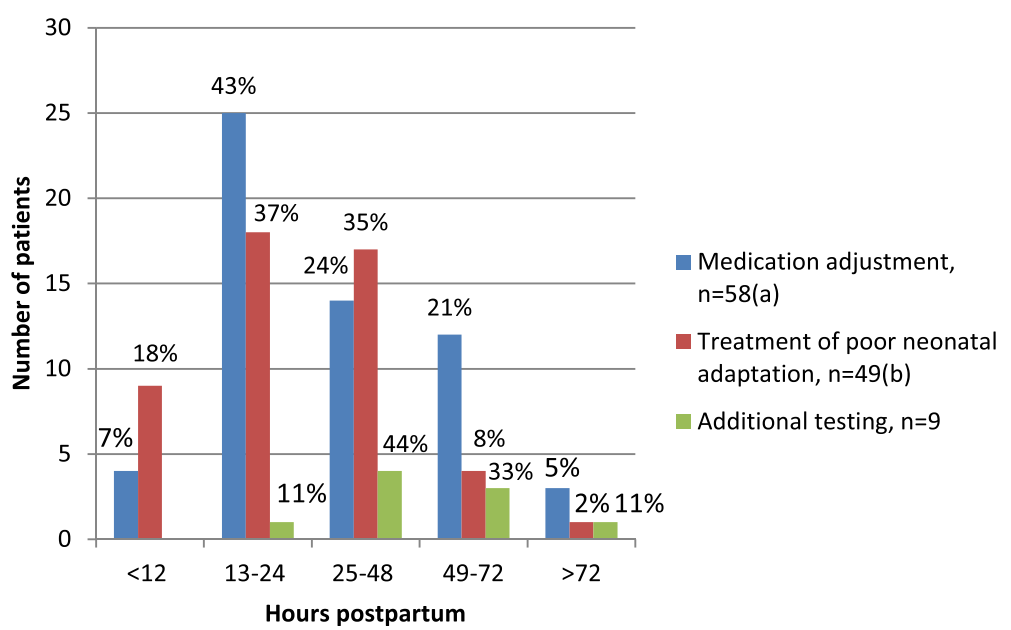

Fig. 2 Time to interventions. a. Data on the time of medication adjustment were missing in 18 mother-infant dyads. b. Data on the time of treatment of poor neonatal adaptation were missing in 27 mother-infant dyads 
Table 2 Comparison of base-line characteristics between mother-infant dyads whereby the final intervention was performed within $48 \mathrm{~h}$ and after $48 \mathrm{~h}$ postpartum

\begin{tabular}{|c|c|c|c|c|}
\hline Variables & $\begin{array}{l}\text { Intervention } \\
<48 \mathrm{~h} \\
n=60\end{array}$ & $\begin{array}{l}\text { Intervention } \\
>48 \mathrm{~h} \\
n=20\end{array}$ & & $p$-value \\
\hline & \multicolumn{3}{|c|}{ Mean (standard deviation) } & \\
\hline \multirow[t]{2}{*}{ Maternal age during delivery (years) } & $33.3(4.7)$ & \multicolumn{2}{|l|}{$31.9(4.3)$} & 0.24 \\
\hline & \multicolumn{3}{|c|}{ Median (interquartile range) } & \\
\hline Duration of observation mother (days) & $4(3-5)$ & $4(3.3-5)$ & & 0.68 \\
\hline \multirow[t]{2}{*}{ Duration of observation infant (days) } & $4(3-5)$ & $4(3.3-5)$ & & 0.79 \\
\hline & \multicolumn{2}{|l|}{ n (\%) } & \multicolumn{2}{|l|}{$\begin{array}{l}\text { Odds ratio } \\
95 \% \mathrm{Cl}\end{array}$} \\
\hline \multicolumn{4}{|l|}{ Marital status } & \multirow[t]{3}{*}{$0.26^{*}$} \\
\hline Single & $6(60.0)$ & $4(40.0)$ & 1 (ref) & \\
\hline Married/living together/LAT ${ }^{a}$ & \multirow[t]{2}{*}{$54(77.1)$} & $16(22.9)$ & $\begin{array}{l}0.44 \\
0.11-1.77\end{array}$ & \\
\hline \multicolumn{3}{|l|}{ Smoking } & & \multirow[t]{3}{*}{$1.00^{*}$} \\
\hline No & $55(76.4)$ & $17(23.6)$ & 1 (ref) & \\
\hline Yes & $5(83.3)$ & $1(16.7)$ & $\begin{array}{l}0.65 \\
0.07-5.93\end{array}$ & \\
\hline Unknown & 0 & 2 & & \\
\hline \multicolumn{4}{|l|}{ Type of psychotropic medication } & \multirow[t]{3}{*}{$1.00^{*}$} \\
\hline Solely antidepressant & $54(75.0)$ & $18(25.0)$ & 1 (ref) & \\
\hline Antidepressant and other type of psychotropic drug & $6(75.0)$ & $2(25.0)$ & $\begin{array}{l}1.00 \\
0.19-5.40\end{array}$ & \\
\hline \multicolumn{4}{|l|}{ Dosage } & \multirow[t]{3}{*}{0.19} \\
\hline $\begin{array}{l}\text { Minimal or below minimal effective daily } \\
\text { dosage }\end{array}$ & $25(83.3)$ & $5(16.7)$ & 1 (ref) & \\
\hline Above minimal effective daily dosage & $35(70.0)$ & $15(30.0)$ & $\begin{array}{l}0.47 \\
0.15-0.69\end{array}$ & \\
\hline \multicolumn{4}{|l|}{ Parity } & \multirow[t]{3}{*}{0.16} \\
\hline Primiparous & $32(82.1)$ & $7(17.9)$ & 1 (ref) & \\
\hline Multiparous & $28(68.3)$ & $13(31.7)$ & $\begin{array}{l}2.12 \\
0.74-6.06\end{array}$ & \\
\hline \multicolumn{5}{|l|}{$\mathrm{HADS}^{\mathrm{b}}$} \\
\hline Anxiety scale not elevated & $27(73.0)$ & $10(27.0)$ & 1 (ref) & \multirow[t]{2}{*}{0.74} \\
\hline Anxiety scale elevated & $32(76.2)$ & $10(23.8)$ & $\begin{array}{l}0.84 \\
0.31-2.33\end{array}$ & \\
\hline Depression scale not elevated & $32(74.4)$ & $11(25.6)$ & 1 (ref) & \multirow[t]{2}{*}{0.95} \\
\hline Depression scale elevated & $27(75.0)$ & $9(25.0)$ & $\begin{array}{l}0.97 \\
0.35-2.69\end{array}$ & \\
\hline No scales elevated & $24(75.0)$ & $8(25.0)$ & 1 (ref) & \multirow[t]{3}{*}{0.96} \\
\hline One or both scales elevated & $35(74.5)$ & $12(25.5)$ & $\begin{array}{l}1.03 \\
0.37-2.89\end{array}$ & \\
\hline Unknown & 1 & 0 & & \\
\hline \multicolumn{4}{|l|}{ Gender infant } & \multirow[t]{3}{*}{0.60} \\
\hline Male & $32(72.7)$ & $12(27.3)$ & 1 (ref) & \\
\hline Female & $28(77.8)$ & $8(22.2)$ & $\begin{array}{l}0.76 \\
0.27-2.13\end{array}$ & \\
\hline
\end{tabular}


Table 2 Comparison of base-line characteristics between mother-infant dyads whereby the final intervention was performed within $48 \mathrm{~h}$ and after $48 \mathrm{~h}$ postpartum (Continued)

\begin{tabular}{|c|c|c|c|c|}
\hline Type of birth & & & & 0.66 \\
\hline Vaginal & $45(76.3)$ & $14(23.7)$ & 1 (ref) & \\
\hline Caesarean Section & $15(71.4)$ & $6(28.6)$ & $\begin{array}{l}1.29 \\
0.42-3.94\end{array}$ & \\
\hline Type of feeding & & & & 0.67 \\
\hline Breastfeeding or mixed feeding & $42(73.7)$ & $15(26.3)$ & 1 (ref) & \\
\hline Exclusively formula & $18(78.2)$ & $5(21.7)$ & $\begin{array}{l}0.78 \\
0.25-2.46\end{array}$ & \\
\hline Gestational age & & & & $0.57^{*}$ \\
\hline$<37$ weeks & $4(100.0)$ & $0(0.0)$ & Not possible to calculate & \\
\hline$\geq 37$ weeks & $56(73.7)$ & $20(26.3)$ & & \\
\hline Finnegan score, highest during observation & & & & $0.50^{*}$ \\
\hline$<4$ & $12(85.7)$ & $2(14.3)$ & 1 (ref) & \\
\hline$\geq 4$ & $48(72.7)$ & $18(27.3)$ & $\begin{array}{l}2.25 \\
0.46-11.06\end{array}$ & \\
\hline
\end{tabular}

Odds ratios and $95 \%$ confidence intervals are presented

*Calculated with Fisher exact test

aLAT: Living apart together

${ }^{b}$ HADS: Hospital anxiety and depression scale

of infants in the group whereby interventions were performed were higher $(p=<0.001)$ and the level of symptoms of anxiety and depression was higher in the intervention group. Also, in mother-infant dyads whereby an intervention was performed, mothers used a relatively higher antidepressant dosage. The type of underlying psychiatric disorder and severity of psychiatric symptoms might attribute to this relationship. PNA does not seem to be related to the antidepressant dosage $[13,24]$. In mother-infant dyads whereof the infants were formula-fed, the intervention rate was higher. An earlier study of our research group showed that formula-fed infants develop more symptoms of poor neonatal adaptation, which could explain this finding [24]. However, other factors, such as the type of psychotropic drugs (some are not compatible with breastfeeding) and severity of psychiatric disorder might also attribute to this relationship. The other base-line characteristics did not differ significantly.

Given the high prevalence of interventions, we would advise to observe all selective antidepressant-exposed mother-infant dyads. Thereby, the observational setting is a matter of debate. There are several disadvantages of hospital admission, including the risk of infection and lack of privacy. However, interventions that were most prevalent; adjustment of the psychotropic medication and establishment of poor neonatal adaptation, have to be performed by professionals $[5,25]$. In the absence of specialized home care in a country, hospital admission is indicated.
Based on our results, we would advise to observe mother-infant dyads for $48 \mathrm{~h}$. This advice is based on our finding that the final intervention was performed within $48 \mathrm{~h}$ in the majority of dyads (75\%), while after an observational period of $24 \mathrm{~h}$ this percentage was only $43 \%$. However, in $25 \%$ of mother-infant dyads the final intervention was performed after $48 \mathrm{~h}$ postpartum. Base-line characteristics of this group of dyads did not differ from base-line characteristics of dyads in which the final intervention was performed within $48 \mathrm{~h}$ postpartum.

It is especially difficult to determine the duration of the observational period for mother-infant dyads with no other indication for hospital admission apart from the exposure to selective antidepressants. Therefore, we performed a post-hoc analysis whereby we excluded dyads with an additional indication for hospital admission directly postpartum, such as a caesarean section or prematurity $(n=165)$. Of the remaining 159 dyads, 60 (37.7\%) needed one or more intervention. The prevalence of interventions was higher in the group of dyads with an additional indication for hospital admission compared to the group of dyads whereby selective antidepressant-exposure was the only indication for hospital admission ( $p$ 0.02). A possible explanation for this finding might be that indications for hospital stay, such as prematurity or fluxus might be associated with selective antidepressant exposure [15, 26].

By interpretation of our results, it is important to hold into account that the percentage of mother-infant 
dyads whereby an intervention was performed is based on 5 types of neonatal and maternal interventions which differ in type and underlying medical problem. This also accounts for the time to interventions, whereby 4 interventions were analyzed.

This study has several limitations. First of all, there were missing data due to the observational design of this study. However, there is no indication that these data were selective. Therefore the reliability of our results is not likely to be affected. Furthermore, hospital admission entails the risk of over diagnosis; some observed effects, which resulted in additional testing or therapy, would not have been observed nor have led to problems in the home setting. Thereby a longer observational period might result in a higher risk of over diagnosis. Apart from the detriment for mother and infant, this may also have affected our study results by increasing the prevalence of interventions. Also, it is important to realize, that this study was performed in a center of expertise for pregnancy and psychiatry. All women were evaluated by a psychiatrist and all infants by a pediatrician. This thorough examination may have resulted in an accurate prevalence. However it is plausible that the prevalence of interventions in this study is higher compared to centers without this specialized care. Furthermore, mother-infant dyads which had been transferred to another hospital were excluded because there was no or a limited observational period in our hospital. As this transfer was based on severe maternal or neonatal pathology in three mother-infant dyads, this may have lead to a relative underestimation of the prevalence of interventions.

\section{Conclusions}

In conclusion, in mother-infant dyads exposed to selective antidepressants during pregnancy, the prevalence of medical interventions was $61 \%$. The most prevalent interventions were adjustment of psychotropic medication and treatment of poor neonatal adaptation. The high prevalence and type of medical interventions requires professional observation of all mother-infant dyads by a multidisciplinary team including a psychiatrist, pediatrician and trained nurses. In the absence of specialized home care, hospital admission is indicated. An observational period of $48 \mathrm{~h}$ seems sufficient for most mother-infant dyads. Further studies that examine predictors of intervention during observation or predictors of a prolonged observation, would be of additional value. If these predictors are known, it might be possible to provide an advise regarding the type and duration of observation on individual basis. In addition, a costeffectiveness analysis would also be essential for development of a guideline.

\section{Appendix}

Table 3 Overview of antidepressants used in our study population

\begin{tabular}{|c|c|}
\hline & $\begin{array}{l}\text { Number of patients } \\
\text { (total 324) }\end{array}$ \\
\hline Paroxetine & 58 \\
\hline Paroxetine and mirtazapine & 3 \\
\hline Paroxetine and olanzapine & 2 \\
\hline Paroxetine and risperidone & 1 \\
\hline Sertraline & 71 \\
\hline Sertraline and mitrazapine & 3 \\
\hline Sertraline and haloperidol & 3 \\
\hline Sertraline and quetiapine & 1 \\
\hline Sertraline and flupentixol & 1 \\
\hline Fluoxetine & 18 \\
\hline Fluoxetine and mirtazapine & 1 \\
\hline Fluoxetine and quetiapine & 1 \\
\hline Citalopram & 58 \\
\hline Citalopram and mirtazapine & 4 \\
\hline Citalopram and amitryptiline & 1 \\
\hline Citalopram, amitriptyline and mirtazapine & 1 \\
\hline Citalopram and olanzapine & 1 \\
\hline Citalopram and pipamperone & 1 \\
\hline Citalopram and haloperidol & 1 \\
\hline Citalopram and lithium & 1 \\
\hline Citalopram and oxaxepam & 1 \\
\hline Venlafaxine & 32 \\
\hline Venlafaxine, mirtazapine and haloperidol & 1 \\
\hline Venlafaxine and haloperidol & 1 \\
\hline Venlafaxine and quetiapine & 5 \\
\hline Venlafaxine and olanzapine & 1 \\
\hline Fluvoxamine & 4 \\
\hline Fluvoxamine and lithium & 1 \\
\hline Mirtazapine & 35 \\
\hline Mirtazapine and clompiramine & 1 \\
\hline Mirtazapine and haloperidol & 4 \\
\hline Mirtazapine and risperidone & 2 \\
\hline Mirtazapine and quetiapine & 1 \\
\hline Mirtazapine and perfenazine & 1 \\
\hline Mirtazapine and flurazepam & 1 \\
\hline Bupropion & 1 \\
\hline Bupropion and quetiapine & 1 \\
\hline
\end{tabular}

\section{Abbreviations}

CI: Confidence interval; HADS: Hospital anxiety and depression scale; LAT: Living apart together; OR: Odds ratio; PPHN: Persistent pulmonary hypertension of the newborn 


\section{Acknowledgements}

None.

\section{Funding}

None.

\section{Availability of data and materials}

Data are available on request.

\section{Authors' contributions}

NK conceptualized and designed the study, collected data, carried out analyses, interpret data, drafted the manuscript and approved the final manuscript as submitted. FdJ conceptualized and designed the study, collected data, carried out analyses, drafted the initial manuscript and approved the final manuscript as submitted. FS conceptualized and designed the study, coordinated and supervised data collection, interpret data, reviewed and revised the manuscript and approved the final manuscript as submitted. KD conceptualized and designed the study, coordinated and supervised data collection, interpret data, reviewed and revised the manuscript and approved the final manuscript as submitted. AH conceptualized and designed the study, coordinated and supervised data collection, interpret data, reviewed and revised the manuscript and approved the final manuscript as submitted. All authors read and approved the final manuscript.

\section{Competing interests}

The authors declare that they have no competing interests.

\section{Consent for publication}

Not applicable.

\section{Ethics approval and consent to participate}

The study was approved by the medical ethics committee of the OLVG west hospital in Amsterdam, the Netherlands.

Because of the observational, retrospective design of this study, informed consent could not be obtained, which was approved by the Medical Ethics Committee as described above. All data were fully anonymized.

\section{Author details}

'Department of Pediatrics, Psychiatry Obstetrics Pediatrics Expert Center OLVG West, Jan Tooropstraat 164, 1061 AE Amsterdam, The Netherlands. ${ }^{2}$ Department of Psychiatry, Psychiatry Obstetrics Pediatrics Expert Center OLVG West, Jan Tooropstraat 164, 1061 AE Amsterdam, The Netherlands. ${ }^{3}$ Department of Gynaecology, Psychiatry Obstetrics Pediatrics Expert Center OLVG West, Jan Tooropstraat 164, 1061 AE Amsterdam, The Netherlands. ${ }^{4}$ Department of Psychiatry, VU Medical Center, de Boelenlaan 1118, $1081 \mathrm{HZ}$ Amsterdam, The Netherlands.

Received: 24 December 2015 Accepted: 7 December 2016

Published online: 11 January 2017

\section{References}

1. Ververs T, Kaasenbrood H, Visser G, Schobben F, de Jong-van den Berg L, Egberts T. Prevalence and patterns of antidepressant drug use during pregnancy. Eur J Clin Pharmacol. 2006;62:863-70.

2. Ray S, Stowe ZN. The use of antidepressant medication in pregnancy. Best Pract Res Clin Obstet Gynaecol. 2014:28:71-83.

3. Kieviet N, Dolman KM, Honig A. The use of psychotropic medication during pregnancy: how about the newborn? Neuropsychiatr Dis Treat. 2013:9:1257-66.

4. Cohen LS, Altshuler LL, Harlow BL, Nonacs R, Newport DJ, Viguera AC, Suri R, Burt VK, Hendrick V, Reminick AM, Loughead A, Vitonis AF, Stowe ZN. Relapse of major depression during pregnancy in women who maintain or discontinue antidepressant treatment. JAMA. 2006;295:499-507.

5. Sie SD, Wennink JMB, van Driel JJ, te Winkel AGW, Boer K, Casteelen G, van Weissenbruch MM. Maternal use of SSRIs, SNRIs and NaSSAs: practical recommendations during pregnancy and lactation. Arch Dis Child Fetal Neonatal Ed. 2012;97:F472-6.

6. Reminick A, Cohen S, Einarson A. Managing depression during pregnancy. Womens Health (Lond Engl). 2013;9:527-35.
7. Hay DF, Pawlby S, Waters CS, Sharp D. Antepartum and postpartum exposure to maternal depression: different effects on different adolescent outcomes. J Child Psychol Psychiatry. 2008:49:1079-88.

8. Wan MW, Salmon MP, Riordan DM, Appleby L, Webb R, Abel KM. What predicts poor mother-infant interaction in schizophrenia? Psychol Med. 2006;37:537.

9. Murray L, Fiori-Cowley A, Hooper R, Cooper P. The impact of postnatal depression and associated adversity on early mother-infant interactions and later infant outcome. Child Dev. 1996;67:2512-26.

10. Byatt N, Deligiannidis KM, Freeman MP. Antidepressant use in pregnancy: a critical review focused on risks and controversies. Acta Psychiatr Scand. 2013;127:94-114.

11. Zuccotti GV, Fabiano V, Manfredini V. Neonates born to mothers using antidepressant drugs. Early Hum Dev. 2012;88 Suppl 2:S84-5.

12. Levinson-Castiel R, Merlob P, Linder N, Sirota L, Klinger G. Neonatal abstinence syndrome after in utero exposure to selective serotonin reuptake inhibitors in term infants. Arch Pediatr Adolesc Med. 2006;160:173-6.

13. Oberlander TF, Misri S, Fitzgerald CE, Kostaras X, Rurak D, Riggs W. Pharmacologic factors associated with transient neonatal symptoms following prenatal psychotropic medication exposure. J Clin Psychiatry. 2004:65:230-7.

14. Sit D, Perel JM, Wisniewski SR, Helsel JC, Luther JF, Wisner KL. Mother-infant antidepressant concentrations, maternal depression, and perinatal events. J Clin Psychiatry. 2011:72:994-1001.

15. Huybrechts KF, Sanghani RS, Avorn J, Urato AC. Preterm birth and antidepressant medication use during pregnancy: a systematic review and meta-analysis. PLoS ONE. 2014;9:e92778.

16. Grigoriadis S, Vonderporten EH, Mamisashvili L, Tomlinson G, Dennis C-L, Koren G, Steiner M, Mousmanis P, Cheung A, Ross LE. Prenatal exposure to antidepressants and persistent pulmonary hypertension of the newborn: systematic review and meta-analysis. BMJ. 2014;348:f6932.

17. Klinger $G$, Merlob P. Selective serotonin reuptake inhibitor induced neonatal abstinence syndrome. Isr J Psychiatry Relat Sci. 2008;45:107-13.

18. Koren G, Finkelstein $Y$, Matsui D, Berkovich M. Diagnosis and management of poor neonatal adaptation syndrome in newborns exposed in utero to selective seretonin/norepinephrine reuptake inhibitors. J Obstet Gynaecol Can. 2009;31:348-50.

19. Bot P. Neonatal effects of exposure to selective serotonin reuptake inhibitors during pregnancy. Arch Dis Child Fetal Neonatal Ed. 2006;91:F153.

20. Zigmond AS, Snaith RP. The hospital anxiety and depression scale. Acta Psychiatr Scand. 1983;67:361-70.

21. Abiodun OA. A validity study of the Hospital Anxiety and Depression Scale in general hospital units and a community sample in Nigeria. Br J Psychiatry. 1994;165:669-72.

22. Finnegan LP, Connaughton JF, Kron RE, Emich JP. Neonatal abstinence syndrome: assessment and management. Addict Dis. 1975;2:141-58.

23. United Office of Drugs and Crime. www.unodc.org. Accessed 3 Jan 2015.

24. Kieviet N, Hoppenbrouwers C, Dolman KM, Berkhof J, Wennink H, Honig A. Risk factors for poor neonatal adaptation after exposure to antidepressants in utero. Acta Paediatr. 2015:104:384-91.

25. Moses-Kolko EL, Bogen D, Perel J, Bregar A, Uhl K, Levin B, et al. Neonatal signs after late in utero exposure to serotonin reuptake inhibitors: literature review and implications for clinical applications. JAMA. 2005;293:2372-83.

26. Palmsten K, Hernandez-Diaz S, Huybrechts KF, Williams PL, Michels KB, Achtyes ED, Mogun H, Setoguchi S. Use of antidepressants near delivery and risk of postpartum hemorrhage: cohort study of low income women in the United States. BMJ. 2013:347:f4877. 